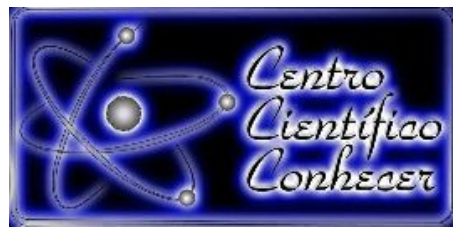

\title{
APLICAÇÃO DE GEOTECNOLOGIAS NA DINÂMICA DE USO E OCUPAÇÃO AGRÍCOLA NO MUNICÍPIO NOVA CANÃ̃ DO NORTE - MT
}

\author{
João Pedro Sauvesuk da Silva ${ }^{1}$; Wesley Vicente Claudino ${ }^{2}$, Edgley Pereira da Silva ${ }^{3}$ \\ ${ }^{1}$ Engenheiro Agrônomo (joaosauvesuk@hotmail.com) Alta Floresta/MT, Brasil \\ ${ }^{2}$ Professor da Faculdade de Ciências Agrárias e Biológicas, UNEMAT, Alta \\ Floresta/MT, Brasil. \\ ${ }^{3}$ Professor Doutor da Faculdade de Ciências Agrárias e Biológicas, UNEMAT, Alta \\ Floresta/MT, Brasil.
}

\section{Recebido em: 02/06/2019 - Aprovado em: 15/06/2019 - Publicado em: 22/07/2019 DOI: 10.18677/Agrarian_Academy_2019a5}

\begin{abstract}
RESUMO
O município de Nova Canaã do Norte - MT vem apresentando ao longo dos últimos anos uma grande expansão agropecuária em virtude de possuir uma forte aptidão dos solos às atividades agrícolas. Contudo, a falta de planejamento e o uso e ocupação inadequados do solo podem prejudicar os recursos naturais, tais como: avanço do desmatamento, erosão do solo, assoreamento de rios e reservatórios, entre outros. Portando, o monitoramento do uso e ocupação do solo se torna imprescindível à prevenção e manutenção desses problemas. O objetivo desse trabalho foi o mapeamento e análise do uso e cobertura do solo do município de Nova Canaã do Norte - MT nos anos de 1990, 2000, 2008, 2010 e 2017. O mapeamento do uso e cobertura do solo foram realizadas analisando imagens dos satélites SPOT-5 e LANDSAT-5 e 8, manipulados pelo software ArcGis 10.1 dos respectivos anos estudados. Nos dois primeiros anos de estudo, as áreas de floresta nativa diminuíram consideravelmente, dando espaço para áreas de pastagem. No ano 2000, a agricultura aparece de forma modesta e ganha espaço nos próximos anos, apossando-se das áreas antigas de pasto. Pode se concluir que entre os anos de 2010 e 2017 a área de floresta nativa pouco diminuiu, mostrando que as áreas abertas estão sendo intensificadas e que praticamente não está ocorrendo a abertura de novas áreas para a pecuária ou agricultura.
\end{abstract}

PALAVRAS-CHAVE: expansão agrícola, geoprocessamento, monitoramento ambiental. 


\title{
APPLICATION OF GEOTECHNOLOGIES IN THE DYNAMICS OF USAGE AND AGRICULTURAL OCCUPATION IN MUNICIPALITY LOCATED AT THE DEFENSE ARCH
}

\begin{abstract}
The municipality of Nova Canaã do Norte - MT has been presenting a great agricultural and cattle expansion over the last years, due to its strong agricultural ability. However, lack of planning and inadequate land use and occupation can damage natural resources, such as: deforestation, soil erosion, silting up of rivers and reservoirs, among others. Therefore, monitoring the use and occupation of the soil becomes essential to the prevention and maintenance of these problems. The objective of this work was the mapping and analysis of the land use and land cover of the municipality of Nova Canaã do Norte - MT in the years 1990, 2000, 2008, 2010 and 2017. The land use and land cover mapping was performed by analyzing images of the satellites SPOT-5 and LANDSAT-5 and 8, manipulated by the ArcGis 10.1 software of the respective years studied. In the first two years of study, the native forest areas decreased considerably, giving space to pasture areas. In the year 2000, agriculture appears modestly and gains space in the next years, taking over the old pasture areas. It can be concluded that between 2010 and 2017 the area of native forest declined slightly, showing that the open areas are being intensified and that there is practically no opening of new areas for livestock or agriculture.
\end{abstract}

KEYWORDS: agricultural expansion, environmental monitoring, geoprocessing.

\section{INTRODUÇÃO}

Nos últimos anos, tem-se verificado um contínuo avanço da fronteira agrícola na região Amazônica, o monocultivo é o principal condicionante, o que vem preocupando a comunidade brasileira às prováveis mudanças ambientais decorrentes do avanço da monocultura na região (SOUZA, 2010).

O uso e ocupação inadequados do solo podem prejudicar toda a integridade de uma área. Segundo Matsushita (2006) as ações do homem no planeta Terra têm gerado grandes impactos nas paisagens através do intenso processo de substituição das áreas naturais, por diferentes tipos de uso do solo, fragmentando as áreas com cobertura florestal.

De acordo com Pena (2018), o desmatamento pode levar ao assoreamento dos rios e reservatórios, quando não há obstáculos para esses sedimentos, função geralmente exercida pela vegetação. E que a expansão agrícola extensiva pode causar a contaminação das águas por fertilizantes e agrotóxicos através do processo natural de lixiviação, infiltram-se no solo e atingem as águas subterrâneas. (CERQUEIRA, 2017).

Para mitigar esses problemas e fomentar o desenvolvimento de políticas públicas para uma gestão sustentável dos recursos naturais, torna-se imprescindível o monitoramento do Uso e da Cobertura do Solo (UCS), através de informações espaço-temporais detalhadas das modificações ocorridas na paisagem (MENDOZA et al., 2011; COELHO, et al., 2014). Portanto, torna-se obrigatório um planejamento integrado do uso e ocupação do solo, visando a importante preservação dos recursos naturais.

De acordo com Câmara e Davis (2001) a tecnologia por Geoprocessamento, utilizada para o tratamento de informação geográfica, técnicas matemáticas e computacionais, influenciando de forma crescente a área de Análise de Recursos Naturais. 
As ferramentas computacionais para o Geoprocessamento, integram dados de diversas fontes permitindo realizar análises complexas, que são de grande importância para um país de dimensão continental como o Brasil. Por ainda existir uma carência enorme de informações, o Geoprocessamento, com seu custo relativamente baixo, tem um enorme potencial de proporcionar conhecimentos adequados para resolução de problemas urbanos, rurais e ambientais. Nova Canaã do Norte é um município brasileiro, situado no extremo norte do estado de Mato Grosso. Sua principal atividade econômica foi a pecuária bovina, seguida por agricultura de subsistência. Atualmente as monoculturas de soja, arroz e milho estão crescendo exponencialmente, necessitando planejamento e manejo integrado do uso e ocupação do solo, objetivando a preservação dos recursos naturais (CÂMARA; DAVIS, 2001).

Mudanças recentes foram observadas no município de Nova Canaã do Norte - MT, áreas tradicionalmente de uso pecuário estão sendo substituídas por áreas de atividades agrícolas. Neste contexto, a escolha do tema de dinâmica de uso e ocupação do solo se justifica, que a partir desses estudos pode-se ter uma noção da dimensão dos problemas causados pela agricultura e pecuária extensiva, tendo como pretensão o manejo integrado do uso e da ocupação do solo.

O presente trabalho teve como objetivo mapear a área de expansão agrícola, no município de Nova Canaã do Norte - MT, por meio de análise temporal, utilizando imagens orbitais e técnicas de geoprocessamento referente ao período de 1990, 2000, 2008, 2010 e 2017.

\section{MATERIAIS E MÉTODOS}

\section{Localização da área de estudo e quadro natural}

O estudo envolveu o município de Nova Canaã do Norte - MT, situado na coordenada geográfica central -10,558 de Latitude e -55,953 de Longitude, ocupa uma área de 596.969,63 hectares (Figura 1) e localizado a $680 \mathrm{~km}$ pela estrada, ou, $551 \mathrm{~km}$ em linha reta da capital do Mato Grosso, Cuiabá.
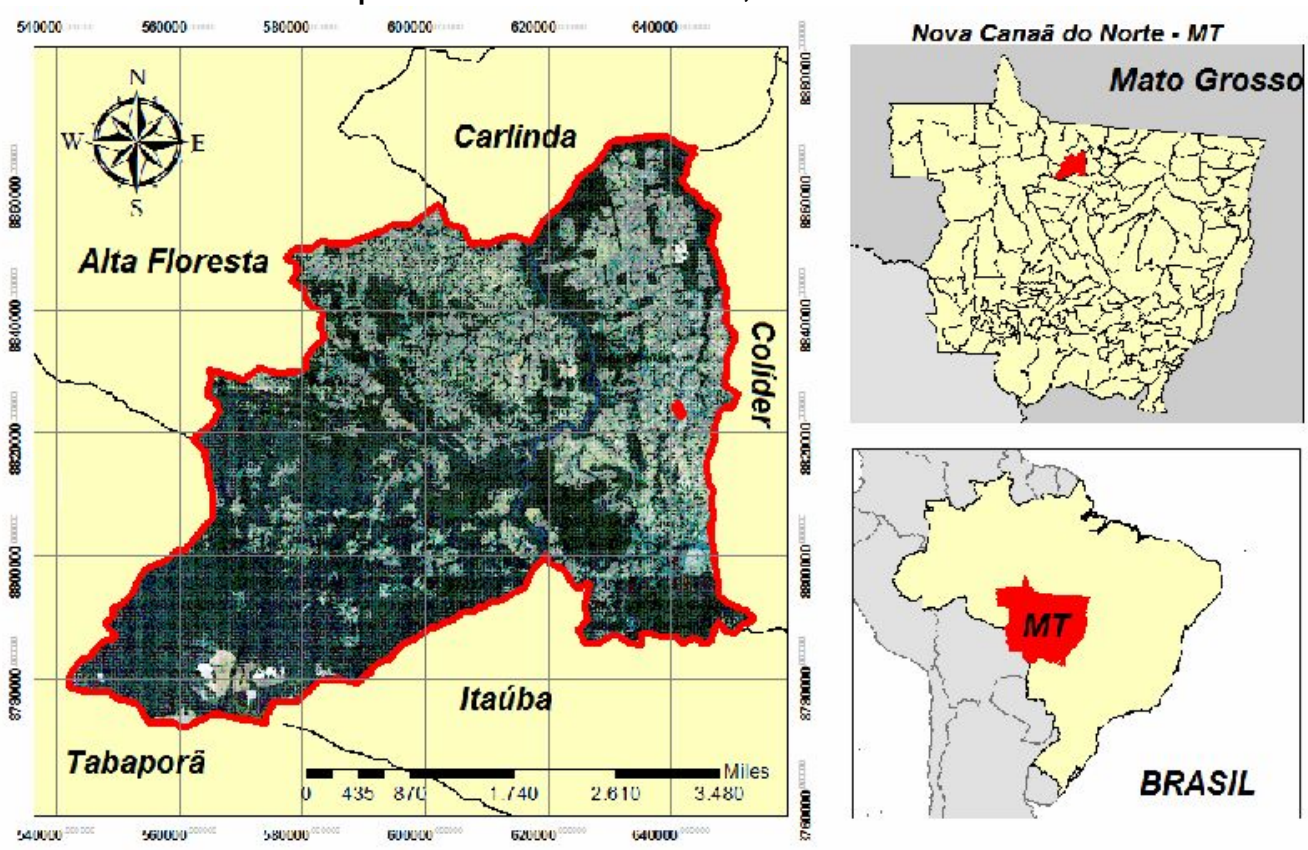

FIGURA 1 - Mapa de Localização da área de estudo, em destaque o município de Nova Canaã do Norte - MT. 
O clima de Nova Canaã do Norte - MT, encontra-se na zona I B3a, caracterizando-se por equatorial continental úmido com estação seca definida da depressão sul amazônico, com temperatura média anual entre 24 e $25^{\circ} \mathrm{C}$. O volume de precipitação pluviométrica é elevado, se estabelecendo entre 2000 e 2300 mm por ano (MATO GROSSO, 2018).

O município é formado por Floresta Ombrófila Aberta e Densa, Floresta Estacional e Cerrado. Os solos variam de Argissolo amarelo e vermelho-amarelo. De acordo com Silva Neto, et al., (2018), são solos de baixa a média fertilidade, de mediana porcentagem de nutrientes e principalmente baixos teores de fósforo e médio teor de potássio, cálcio, magnésio e matéria orgânica.

De acordo com o relevo da maior parte do município apresenta altitudes entre 250 a 300 metros, que corresponde aproximadamente $49,5 \%$ da área total.

\section{Materiais utilizados}

Nesse estudo foram manipuladas imagens orbitais do Spot-5 e Landsat-5, obtidas por sensoriamento remoto. Foram também utilizadas técnicas de geoprocessamento na produção de informações sobre a expansão agrícola. Realizando uma análise quantitativa das áreas e diagnosticando os diferentes usos do solo.

O mapeamento da distribuição hidrográfica de Nova Canaã do Norte foi realizado através de um banco de dados disponibilizado pela Secretaria Estadual do Meio Ambiente - SEMA, este apresenta toda a hidrografia e nascentes presentes no município.

Para cobrir toda a extensão territorial do município, foram utilizadas sete imagens orbitais do Satélite SPOT-5, sendo elas o mosaico das cenas 1628, 1629, $1694,1695,1755,1756$, datadas do ano de 2008, com a referência espacial WGS 1984 UTM Zone 21S. Foi utilizada também imagem do sensor do satélite LANDSAT5 dos anos de 1990, 2000 e 2010, datadas entre o mês de maio e agosto e do LANDSAT-8 para ano de 2017, foram utilizadas as cenas 227067 e 227068 do mês de maio.

\section{Processamento das Imagens}

Para obter as áreas de uso e ocupação do solo do município, foi feita uma classificação das imagens dos sensores, LANDSAT-5 e SPOT-2008, com uma resolução espacial de $30 \mathrm{~m}$ e $2,5 \mathrm{~m}$ respectivamente. Constituiu-se de uma classificação supervisionada, do algoritmo de Máxima Verossimilhança e de distância mínima. As classes serão interpretadas como (1) Floresta nativa, (2) Solo exposto, (3) Pastagem produtiva e (4) Pastagem levemente degradada. Para a classificação supervisionada foram coletadas pelo menos 3 amostras para cada classe, com no mínimo 200 pixels por cada classe. Agricultura, garimpo, espelhos d'água e mancha urbana foram vetorizados manualmente.

A manipulação das imagens foi realizada no software ArcMap 10.1 (versão demonstrativa), e foram realizadas operações de processamento, tais como: classificações, cruzamentos e análises espaciais, visando à edição de um mapa.

\section{Mapeamento do uso e cobertura do solo}

Para geração do mapa de uso e cobertura do solo, foram levantadas informações temáticas obtidas a partir de interpretação visual de diferentes imagens. 
$\mathrm{Na}$ determinação das classes de uso do solo foi realizado uma classificação do tipo supervisionada sendo coletado no mínimo 3 amostras puras para cada classe. Foi quantificada a área de cada classe por meio da tabela de atributos, para tonar visível o tamanho que cada classe ocupa na área de estudo. A classificação supervisionada foi confeccionada através da seleção manual de amostras de treinamento, referentes a cada classe de uso, baseando-se em chaves de interpretação visual (Figura 2).

\begin{tabular}{|c|c|c|}
\hline Imagens Orbitas & Classes-uso e cobertura & Descrição das classes \\
\hline & Pastagem produtiva & $\begin{array}{c}\text { Área composta por } \\
\text { gramineas produtivas }\end{array}$ \\
\hline & $\begin{array}{c}\text { Pastagem levemente } \\
\text { degradada }\end{array}$ & $\begin{array}{c}\text { Área composta por } \\
\text { gramineas com algum } \\
\text { nivel de degradação }\end{array}$ \\
\hline & Floresta nativa & $\begin{array}{c}\text { Área composta apenas } \\
\text { por arbóreas }\end{array}$ \\
\hline & Solo exposto & $\begin{array}{c}\text { Considerados como solos } \\
\text { descobertos e sem a } \\
\text { presença de áreas verdes } \\
\text { ou edificações }\end{array}$ \\
\hline
\end{tabular}

FIGURA 2- Chave para Identificação das classes de uso e cobertura do solo

\section{RESULTADOS E DISCUSSÃO}

No município de Nova Canaã do Norte a colonização do município e expansão inicial urbana se deu a partir das proximidades de recursos hídricos e de áreas planas, localizada na região nordeste e leste do município, as quais são mais fáceis de serem trabalhadas e possuem recursos essenciais para a sobrevivência e produção de alimentos.

O município possui uma ampla malha hidrográfica (Figura 3), com aproximadamente 2.950,15 quilômetros de cursos d'água, e ainda se constitui de dois grandes rios, o Teles Pires e o Apiacá, que apresentam o comprimento dentro do perímetro municipal de 155,70 e $59,10 \mathrm{~km}$ respectivamente. O município ainda apresenta 652 nascentes, localizadas em grande quantidade na região leste, onde se iniciou o processo de urbanização e exploração agropecuária.

Fearnside (2005), diz que a vegetação retém a precipitação, reduzindo a quantidade de água que chega aos cursos d'água, permitindo assim um padrão regular dos rios no bioma amazônico. Já em áreas abertas, a chuva escoa rapidamente, formando as cheias, seguidas por períodos de grande redução os cursos d'água, como ocorre em áreas extensas de pasto e também no cerrado. 


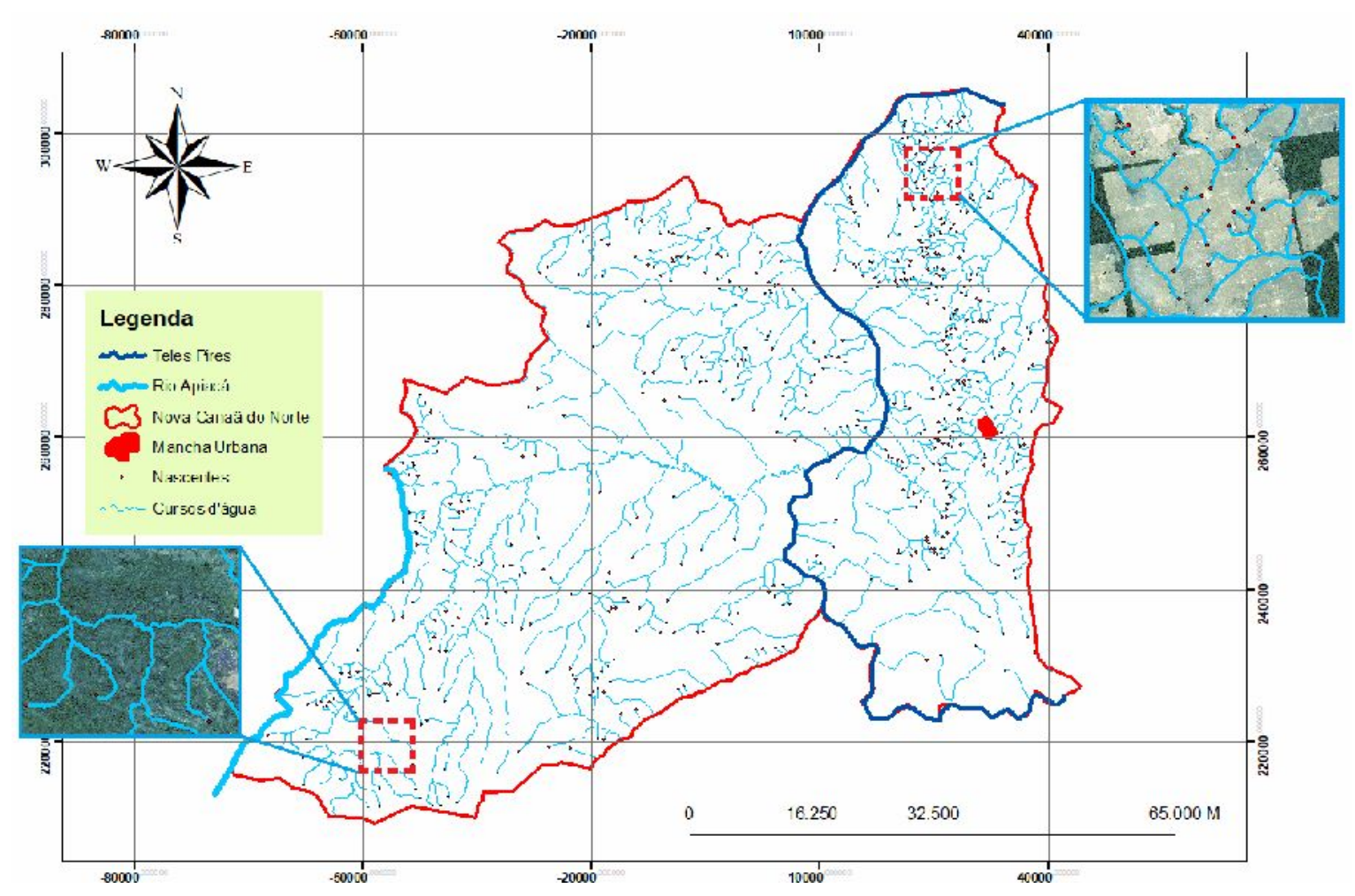

FIGURA 3 Mapa da malha hidrográfica e nascentes do município de Nova Canaã do Norte - MT.

As áreas mais planas e também com a menor altitude se localizam na região Norte e Leste do município, onde ocorreu o início da exploração agropecuária e também a expansão da urbanização. Já a região Sul apresenta a maior altitude, com picos de aproximadamente 475 metros, localizada numa área de transição entre o bioma amazônico e o cerrado (Figura 4). O relevo plano, juntamente com a grande disponibilidade de recursos hídricos, permitiu que o município se estabelecesse e se expandisse inicialmente ao leste do rio Teles Pires, tendo a agropecuária como sua principal atividade econômica. A região sul, foi ocupada posteriormente, por apresentar um relevo mais íngreme e, portanto, com menor aptidão agrícola. De acordo com Silva Neto, et al. (2018), terrenos que geralmente possuem relevo plano a suave ondulado, facilitam o emprego de práticas agrícolas mecanizadas. 


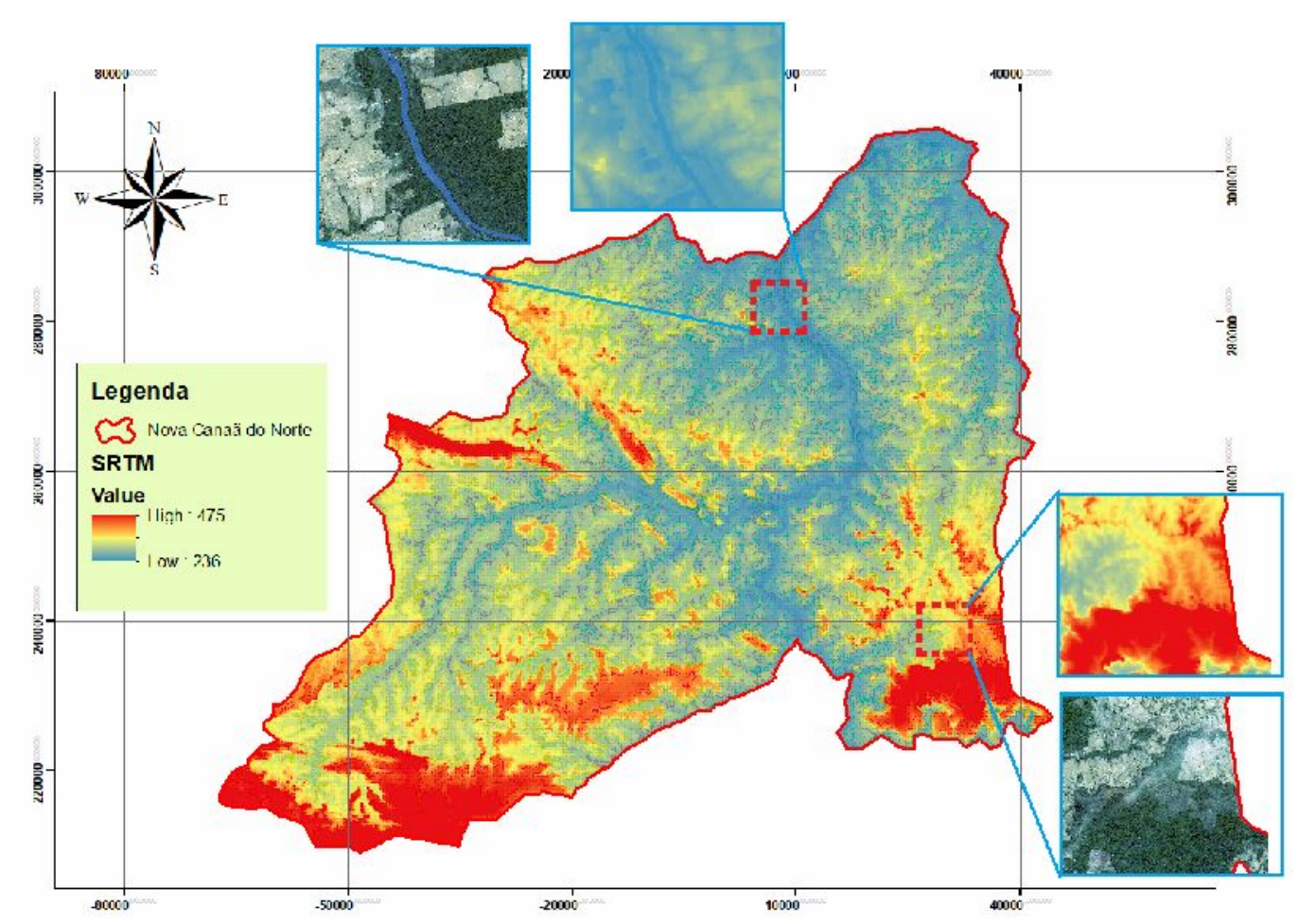

FIGURA 4 Mapa de relevo do município de Nova Canaã do Norte - MT.

\section{Uso e ocupação dos solos}

No ano de 1990, 14 anos após as primeiras movimentações com fins de colonização, o município apresentava pouca área explorada, sendo a sua maioria destinada para a bovinocultura de corte e leite praticada de forma extensiva, grande parte da população produzia de forma subsistente. Tendo isso em consideração, o predomínio do uso da cobertura do solo, da área explorada, no ano de 1990, era de Pastagem degradada, seguida de Pastagem produtiva, como é possível visualizar na Figura 5.

Na década de 1970, o Governo Federal subsidiou a construção de rodovias e a implantação de diversos mecanismos de incentivo à colonização que, juntamente com investimentos de capitais estrangeiros na extração de recursos minerais, promoveram a consolidação de uma infraestrutura capaz de alavancar o desenvolvimento das áreas limítrofes da floresta, favorecendo a transformação de grandes áreas de mata em áreas cultiváveis, atualmente a Amazônia vem se transformando em endereço cobiçado para expansão da fronteira produtiva da pecuária extensiva seguida da agricultura intensiva (TAVORA, 2015).

De acordo com Araújo (2008) existem ciclos econômicos em que qualquer município de expansão agrícola apresenta: desmatamento - pastagem - agricultura. No ano de 1990, o município de Nova Canaã do Norte apresentava o ciclo de desmate para a abertura de áreas de pastagem. A fragmentação florestal foi contínua e paralela à inclusão dos ciclos econômicos do Município.

No mapa de Uso e Ocupação dos Solos do ano de 1990, há um total de $596.969,66$ ha, sendo que dentro desta área foram classificados 525.138,94 ha de floresta nativa, o que equivale a $88 \%$ da área total, $4.103,09$ ha de rios que corresponde a $0,68 \%$ da área total, $11.346,57$ ha pastagem produtiva, que representa $1,90 \%$ da área total, $53.436,38$ ha de pastagem com algum nível de degradação, retratando $8,95 \%$ da área total, $2.532,22$ ha de solo exposto, AGRARIAN ACADEMY, Centro Científico Conhecer - Goiânia, v.6, n.11; p. 55 2019 
representando $0,42 \%$ da área total, além de 160,50 e 251,60 hectares que constituem Mancha urbana e Garimpo, respectivamente. A agricultura existia de forma singela, apenas para consumo interno nas propriedades rurais.

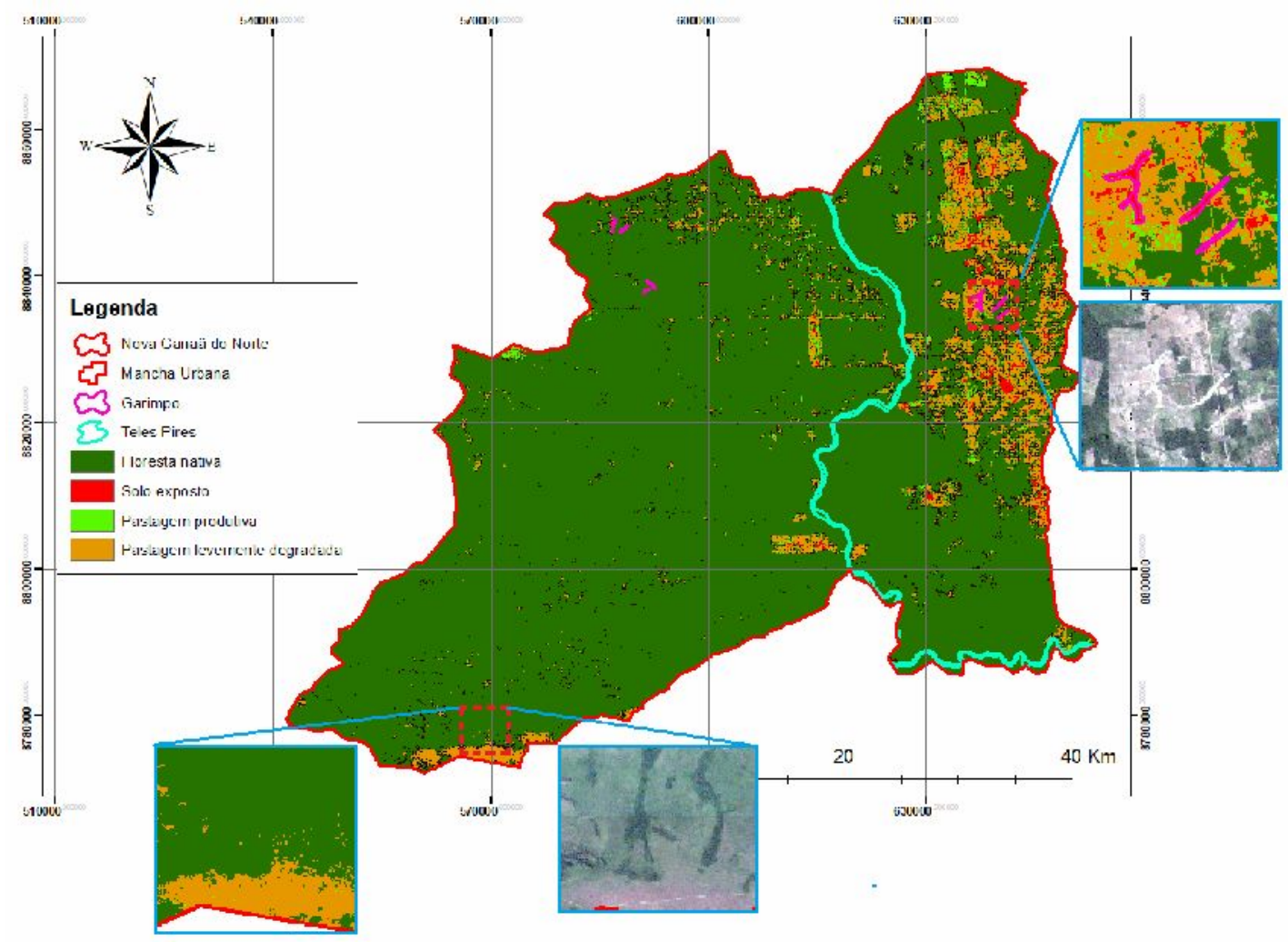

FIGURA 5 Mapa de uso e ocupação do solo do ano de 1990.

No ano de 2000, já é possível observar o surgimento de mais áreas abertas ao redor da zona urbana, também destinada à bovinocultura de corte e leite, sendo principalmente constituídas de Pastagem com algum nível de degradação e Pastagem produtiva (Figura 6). O relevo plano e a boa distribuição dos recursos hídricos permitiram uma boa disseminação das áreas de produção nessa região do município. A agricultura começa a aparecer de forma delicada e progressiva, contudo, a área de Floresta nativa diminuiu consideravelmente, dando espaço a extensas áreas de pastagem. Produtores sem conhecimento técnico optavam por desmatar áreas nativas ao reformar e intensificar as áreas já abertas, assim que seus territórios diminuíam de produção, justificando a substituição das florestas por áreas de pastagem.

Dias-Filho (2015) diz que na época, a pecuária só se tornava lucrativa devido ao baixo preço de aquisição da terra, subsidiada pela SUDAM (Superintendência do Desenvolvimento da Amazônia). Além disso, a venda da madeira extraída na própria área gerava recursos suficientes para pagar o custo da terra, o desmatamento, a queimada, a plantação da pastagem e, ainda, a aquisição de todo o gado necessário para iniciar o rebanho. O proprietário, então, usufruía da fertilidade proveniente das cinzas da queimada por alguns poucos anos e depois abandonava a terra.

Segundo o INPE (2018), a taxa estimada pelo Projeto de Monitoramento do Desmatamento na Amazônia Legal por Satélite (PRODES), do Instituto Nacional de Pesquisas Espaciais (INPE), corresponde a $7.900 \mathrm{~km}^{2}$ de corte raso no período de 
agosto de 2017 a julho de 2018 da Amazônia Legal, tem ligação direta com pastagem e com danos ao meio-ambiente causados diretamente pela criação de gado.

Antigamente, as tecnologias utilizadas voltavam-se, exclusivamente, para a eficiência do processo de derrubada de florestas e à exploração de seus recursos, avançando sem nenhuma forma de planejamento. Dentre as principais atividades econômicas que interagem com a floresta Amazônica, a pecuária talvez seja a mais polêmica. Por um lado, apresenta um caráter avassalador devido a exigência de grandes áreas de pastagens formadas por meio da derrubada e queima da mata e, por outro, tem um perfil pioneiro por estabelecer o direito da posse da terra e facilitar o posterior uso do solo para culturas agrícolas mecanizadas (DIAS-FILHO, 2015).

No mapa de Uso e Ocupação dos Solos do ano 2000, há um total de $596.969,66$ ha, sendo que dentro desta área foram classificados $432.797,89$ ha de floresta nativa, o que equivale a $72,50 \%$ da área total, $3.830,45$ ha de rios que corresponde a $0,65 \%$ da área total, $63.574,74$ ha pastagem produtiva, que representa $10,65 \%$ da área total, $85.060,95$ ha de pastagem com algum nível de degradação, retratando $14,25 \%$ da área total, $9.814,45$ ha de solo exposto, representando $1,64 \%$ da área total e ainda, $1.634,36$ ha de agricultura, que ainda representa apenas $0,27 \%$ da área total do município. Neste ano, extensões com monoculturas começaram a aparecer de forma modesta, em áreas que eram anteriormente pastagem, em sua maioria com algum nível de degradação.

Ichihara (2003) salienta que falhas no planejamento e na condução das propriedades da região amazônica têm provocado a redução significativa do tempo de vida útil das pastagens e que áreas que estão formadas há mais de duas décadas e não receberam o correto manejo, estão hoje em processo de degradação.

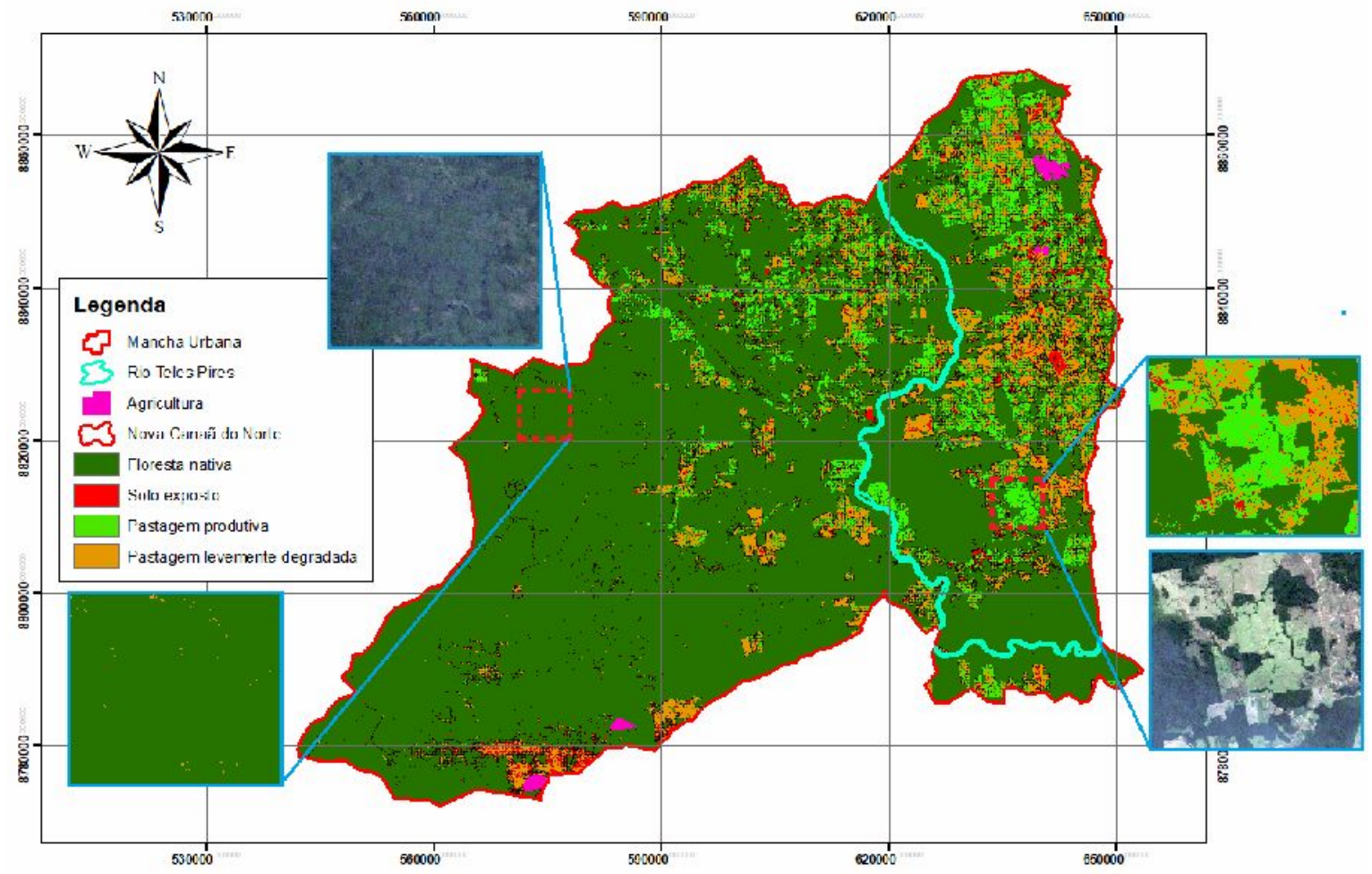

FIGURA 6 Mapa de Uso e cobertura do solo do ano de 2000. 
Para o ano de 2008 (Figura 7) foram utilizadas imagens do satélite SPOT, que possui resolução espacial de 2,5 metros, permitindo assim um maior detalhamento e consequentemente uma maior fidelidade na classificação dos pixels. Em 2008, podese verificar que praticamente toda a área com uma boa aptidão agrícola, relevo plano e boa distribuição hídrica ao leste do Rio Teles Pires já foi explorada, em sua grande maioria com uso de pastagens para bovinocultura de corte e leite, ainda praticada de forma extensiva. Já ao oeste do Rio Teles Pires, constata-se o aumento das áreas de pastagem em sua maioria nas regiões com menor altitude, e uma acentuação da agricultura na região sul do município.

Em 2008, o mapa de uso e ocupação do solo apresentou uma área de $311.165,29$ hectares de floresta nativa, representando $52 \%$ da área total, mostrando que a área natural diminuiu aproximadamente 121.000,00 hectares, o que originou extensas áreas de pastagem. A área de pastagem produtiva nesse ano subiu para $118.981,60$ hectares, representando $19,93 \%$ da área total. A área de pastagem como algum nível de degradação também aumentou, para 124.426,50 representando $20,85 \%$ da área total, proveniente de pastagens que antes eram produtivas e que sem o manejo correto, passaram a produzir menos como uma área recém-aberta. As áreas com solo exposto também aumentaram, originária em sua maioria de pastagens com um nível de degradação mais acentuado, sem as práticas corretas de manejo, atingiram esse nível de erosão, apresentando 28.887,47 hectares, atuando com $4,83 \%$ da área total do município. A área destinada a agricultura se desenvolveu significativamente para 9.767,86 hectares, representando agora $1,63 \%$ da área total.

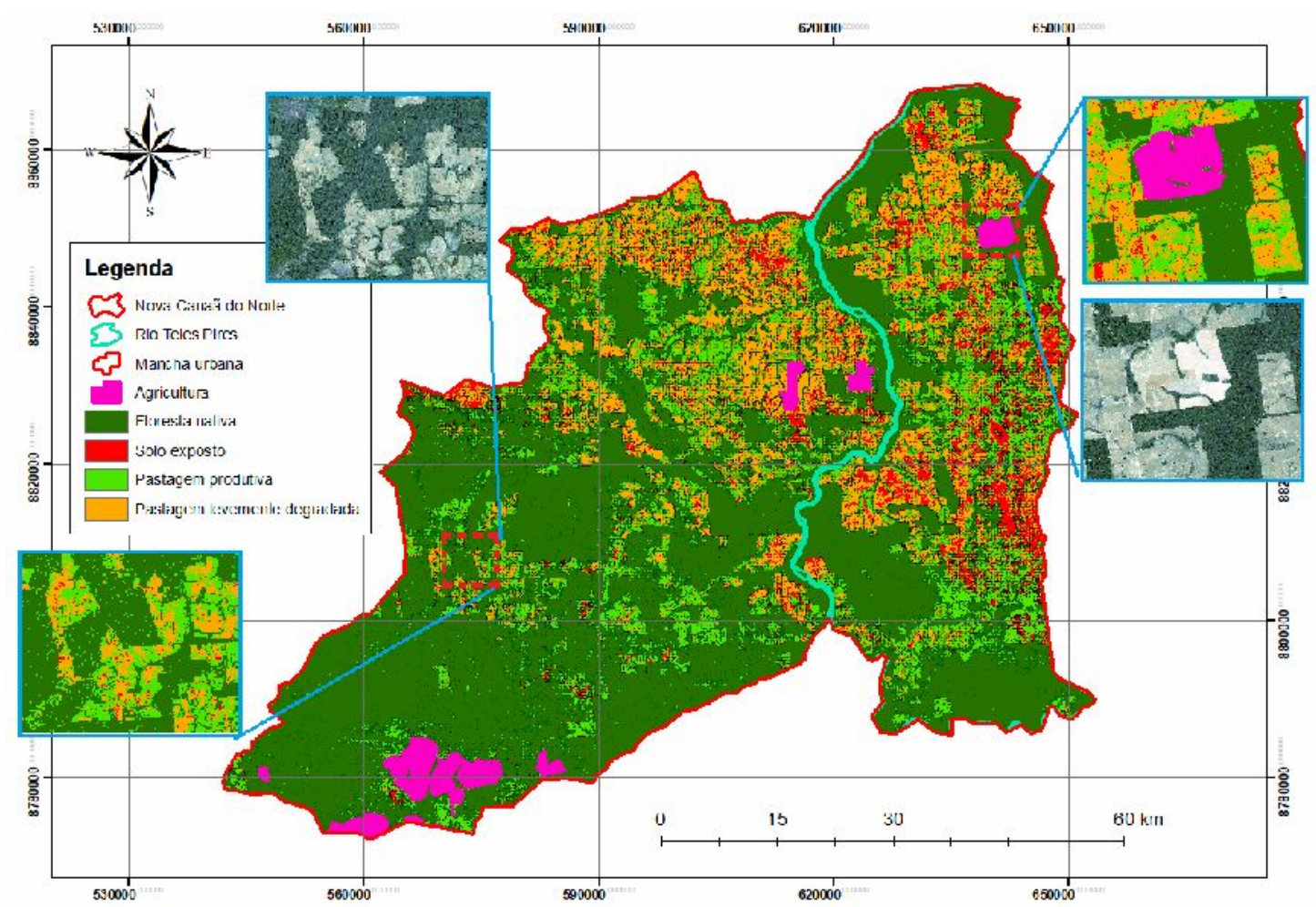

FIGURA 7 Mapa de uso e ocupação do solo do ano de 2008 
No ano de 2010, as áreas de floresta nativa continuaram diminuindo, como desde a colonização do município, dando lugar a áreas de pasto, que em pequena escala deram espaço as áreas de agricultura, ocupando primeiramente as áreas com melhor aptidão agrícola, relevo plano e boa disposição hídrica (Figura 8).

Para o ano de 2010, o mapa de Uso e Ocupação dos Solos obtidos pelo método de classificação supervisionada por máxima verossimilhança, exibiu um total de 303.695,52 hectares de Floresta nativa, resultando nesse ano $50,80 \%$ da área total do município. A área de Pastagem produtiva diminuiu em comparação ao ano de 2008, apresentando 112.752,14 hectares, diminuindo aproximadamente $1 \%$, e ocupando $18,88 \%$ da área total do município. A área de Pastagem levemente degradada também diminuiu, caindo para 120.202,69 hectares e representando $20,13 \%$ da área total. Já a classificação de Solo exposto subiu consideravelmente, proveniente de áreas de pasto com níveis de degradação excessivos, com $41.703,50$ hectares nesse ano, sendo 9,36\% da área total.

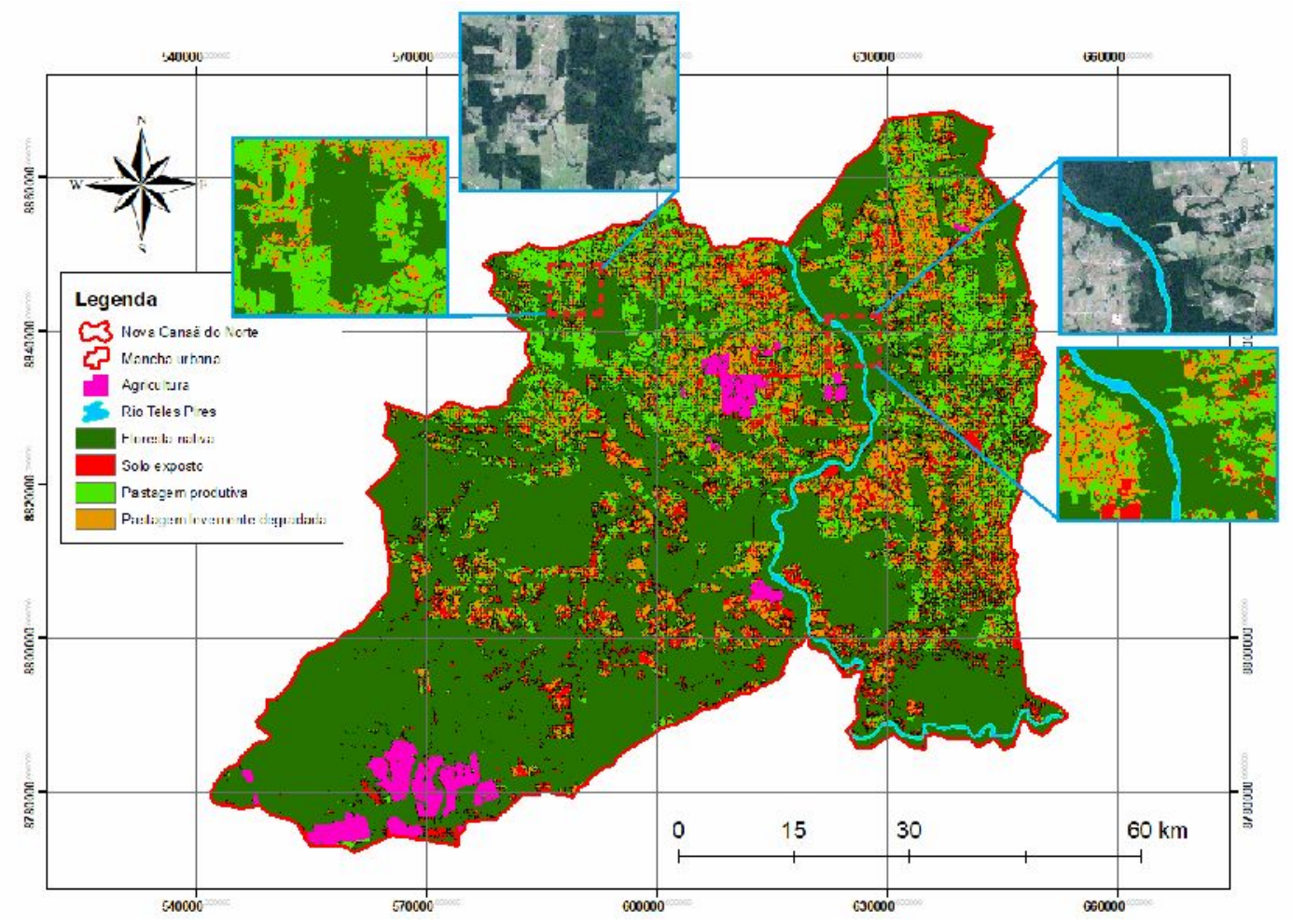

FIGURA 8 Mapa de uso e ocupação do solo do ano de 2010

$\mathrm{Na}$ Figura 9, corresponde ao ano de 2017, 41 anos após as primeiras movimentações de colonização do município, a área de Floresta nativa ainda diminui, em sua grande maioria de forma ilegal, dando espaço a extensas áreas de pasto para uma pecuária extensiva insustentável, não se preza a intensificação de áreas já abertas e o correto manejo para a conservação do solo, assim mantendo um bom nível de produtividade. As áreas de pastagem produtiva diminuíram de forma abrupta, reforçando a ideia de que os produtores não realizam o manejo de forma correta, exaurindo o solo. A área destinada a Floresta nativa caiu para 298.879,63, desta vez, representando $50,06 \%$ da área.

A área de Pastagem produtiva diminuiu aproximadamente $56 \%$ do ano anterior, com apenas 63.374,29 hectares e representando 10,16\% da área total do 
município. A área de pastagem levemente degradada aumentou subitamente para $185.745,86$, representando agora $33,07 \%$ da área total do município. Por outro lado, a área destinada a agricultura também teve um aumento, de aproximadamente 15.000 hectares, com $28.160,74$ hectares agora, representando $4,71 \%$ da área total do município (Figura 10).

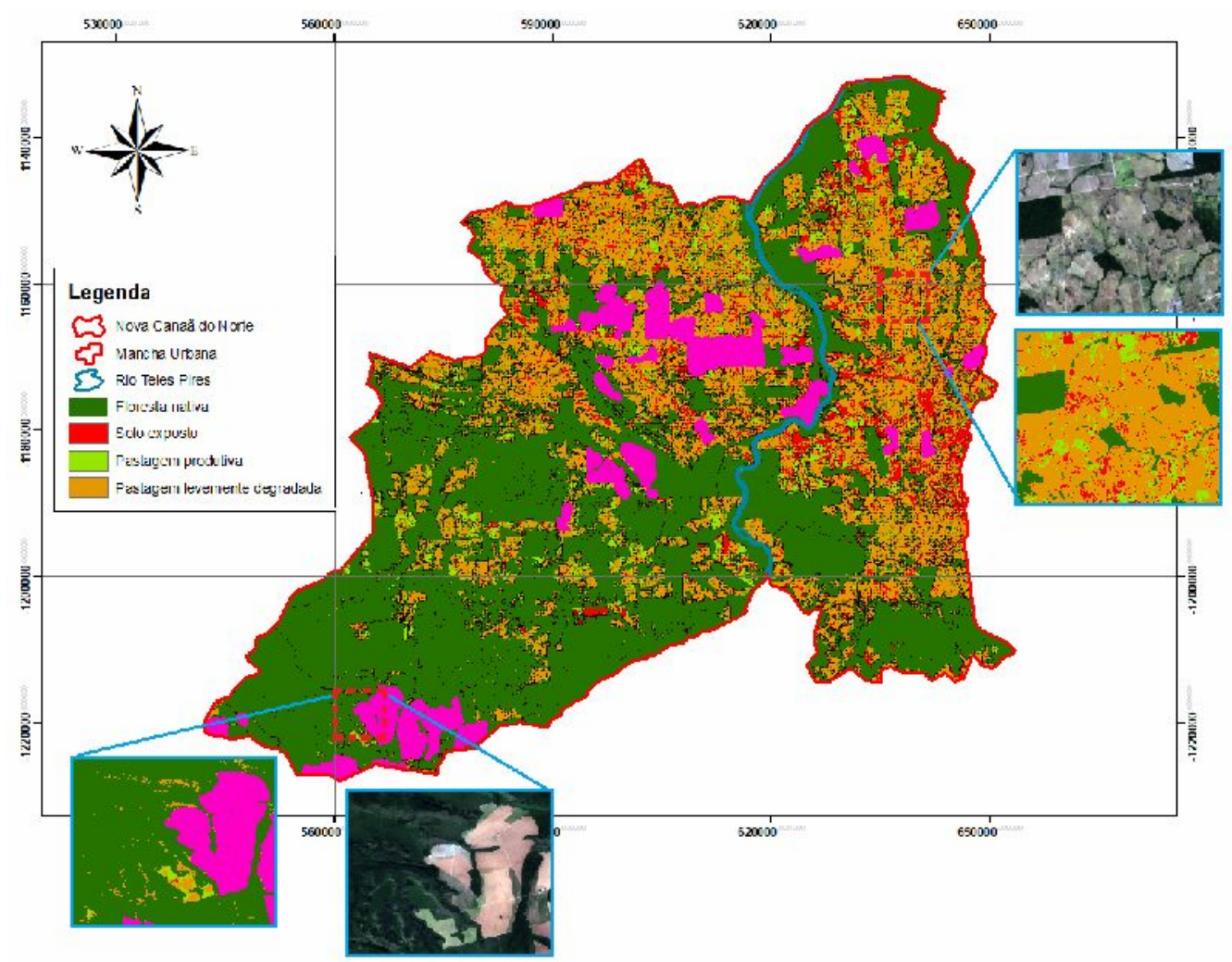

FIGURA 9 Mapa de uso e ocupação do ano de 2017

TAVORA (2015), destaca que a Amazônia vem se transformando em endereço cobiçado para expansão da fronteira produtiva da pecuária extensiva seguida da agricultura intensivas e que as áreas ocupadas com pastagens são muito mais viáveis de serem convertidas em área com soja e, no próprio período em que se dá essa conversão, iniciar-se a produção de soja.

Dias-Filho (2012) diz que integrar sistemas de produção de grãos e pecuária é opção viável para intensificar, elevando os níveis de produtividade e diversidade da propriedade rural, bem como para recuperar pastagens degradadas, reduzir os riscos de degradação e reduzir desmatamentos. Isso justifica o aumento significativo da agricultura e também a diminuição dos níveis de desmatamento de áreas de floresta nativa, nos dois últimos anos de estudo. 


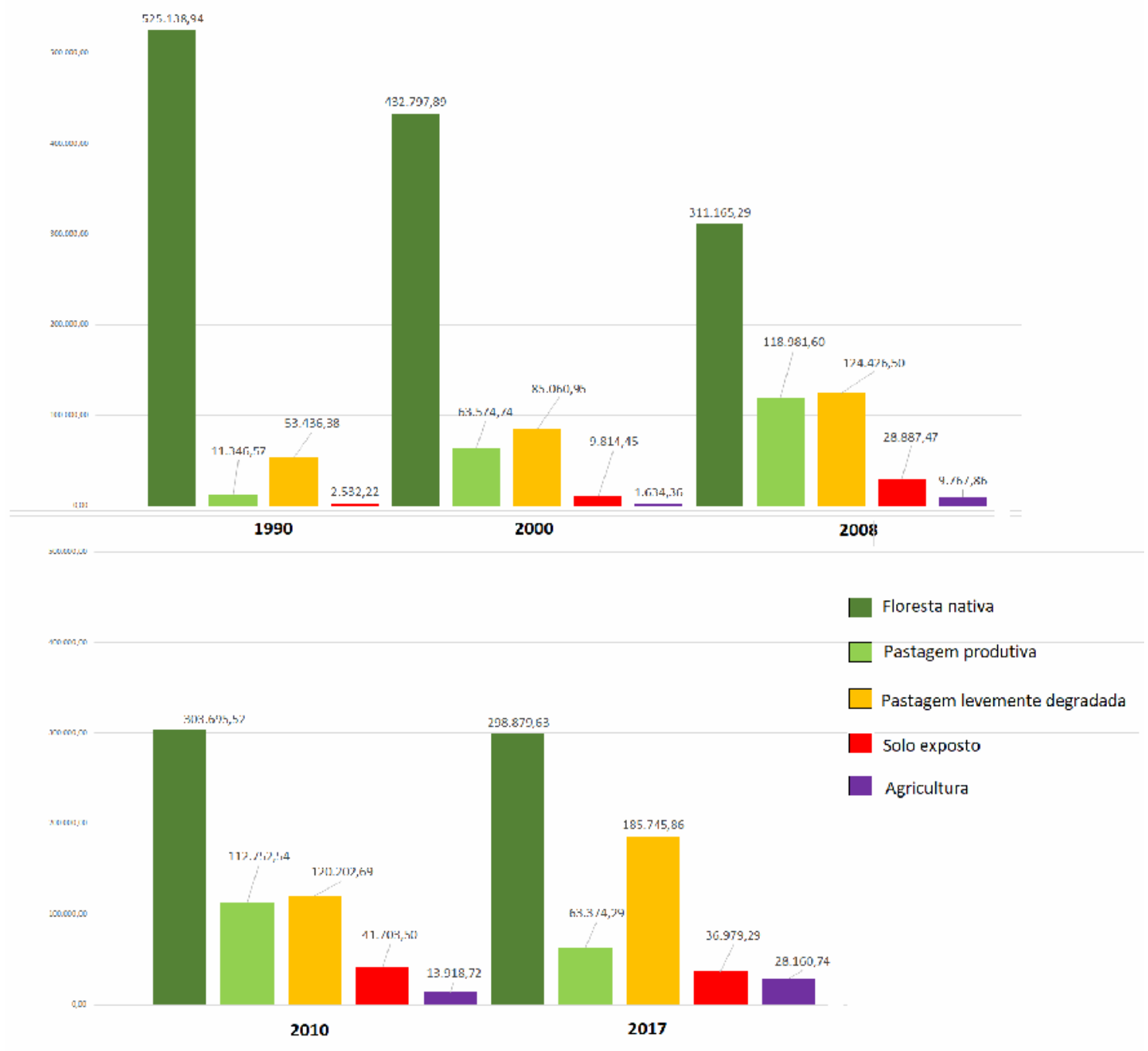

FIGURA 10 Gráfico de área em hectares para cada uso do solo em cada ano de estudo.

\section{CONCLUSÕES}

Em uma área com grande extensão territorial, como no município de Nova Canaã do Norte - MT, a Geotecnologia se torna imprescindível para uma análise dinâmica do uso e cobertura do solo.

Os dados do estudo mostram que no início da colonização do município, grandes áreas de floresta nativa deram espaço para áreas de pastagem através do desmate e queima, por outro lado, o estudo também mostra que quanto mais próximo dos dias atuais, menos áreas de floresta estão sendo desmatadas.

A dinâmica de expansão da substituição da floresta apresenta padrão de forte aceleração no período de 1990 a 2008 e de desaceleração no período de 2008 a 2017, para o município inteiro. Enquanto no ano de 1990 a ocupação do solo com floresta nativa representava $88 \%$ da área total do município, em 2017 representa apenas $50,06 \%$.

No ano de 2000, a agricultura começa a aparecer de forma modesta, representando apenas $0,27 \%$ da área total do município, substituindo áreas de pastagens. Já no ano de 2017 a área ocupada com agricultura subiu para $4,71 \%$ da área total. 
Pode-se concluir que com grandes extensões de áreas abertas, não há mais a necessidade de desmatamento, mas sim a intensificação das áreas já exploradas, aumentando a produtividade.

\section{REFERÊNCIAS}

ARAÚJO, R. A. Florística e estrutura da comunidade arbórea em fragmento florestal urbano no município de Sinop, Mato Grosso. 2008. 132 p. Dissertação (Mestrado em Ciências Florestais e Ambientais) - Faculdade de Engenharia Florestal, Universidade Federal de Mato Grosso, Cuiabá, 2008.

CÂMARA, G.; DAVIS, C. Introdução ao geoprocessamento. Instituto Nacional De Pesquisas Espaciais (Inpe), São José dos Campos, v. 1, n. 1, p. 1-5, 2001. Disponível em: <http://www.obt.inpe.br/OBT/noticias/inpe-estima-7-900-km2-dedesmatamento-por-corte-raso-na-amazonia-em-2018>. Acesso em: 28 maio 2019.

CERQUEIRA, W. A agropecuária e os problemas ambientais. Mundo Educação. Goiânia. 2017. Disponível em: <https://mundoeducacao.bol.uol.com.br/geografia/aagropecuaria-os-problemas-ambientais.htm>. Acesso em: 28 de maio de 2019.

COELHO, V. H. R.; MONTENEGRO, S. M. G. L.; ALMEIDA, C. N.; LIMA, E. R. V.; NETO, A. R.; MOURA, G. S. S. Dinâmica do uso e ocupação do solo em uma bacia hidrográfica do semiárido brasileiro. Revista Brasileira de Engenharia Agrícola Ambiental. v.18, n.1, Campina Grande. 2014.

DIAS-FILHO, M. B. Desafios da produção animal em pastagens na fronteira agrícola brasileira. Belém: Embrapa Amazônia Oriental, 2012. 36 p. (Embrapa Amazônia Oriental. Documentos, 382).

DIAS-FILHO, M. B. Desafios e perspectivas na recuperação de pastagens degradadas na Amazônia. Belém, Embrapa Amazônia Oriental, 2015. 38p. (Embrapa Amazônia Oriental. Documentos, 414).

FEARNSIDE, P.M. Desmatamento na Amazônia brasileira: História, índices e consequências. Megadiversidade, Belo Horizonte, v. 1, n. 4, p. 113-123, 2005.

ICHIHARA, M. S. Desmatamento e recuperação de pastagens degradadas na região amazônica: uma abordagem através das análises de projetos. 2003. 124 p. Dissertação (Mestrado em Ciências) - Universidade de São Paulo, Escola Superior de Agricultura Luiz de Queiroz, 2003.

INPE - Instituto Nacional de Pesquisas Espaciais. INPE estima 7.900 km2 de desmatamento por corte raso na Amazônia em 2018. 2018. Disponível em: $<$ http://www.obt.inpe.br/OBT/noticias/inpe-estima-7-900-km2-de-desmatamento-porcorte-raso-na-amazonia-em-2018>. Acesso em 12 de abril de 2019.

MATSUSHITA, B.; XU, M.; FUKUSHIMA, T. Characterizing the changes in landscape structure in the Lake Kasumigaura, Japan using a high-quality GIS dataset. Ladscape and Urban Planning, Nova York, v.78, n. 3, p.241-250, 2006. 
MENDOZA, M. E.; GRANADOS, E. L.; GENELETTI, D.; PÉREZ-SALICRUP, D. R.; SALINAS, V. Analysing land cover and land use change process at watershed level: A multitemporal study in the Lake Cuitzeo Watershed, Mexico (1975-2003). Applied Geography, Nova York, v.31, n. 1, p.237-350, 2011.

MATO GROSSO. Unidades Climáticas do Estado de Mato Grosso. Disponível em: <http://www.dados.mt.gov.br/publicacoes/dsee/climatologia/rt/DSEE-CL-RT-002A021.pdf>. Acesso em: 25 abril de 2019.

PADILHA, R. M.; SOUZA, C. A. Características morfométricas do relevo e drenagem da bacia hidrográfica do rio Carapá nos municípios de Colíder e Nova Canaã do Norte - MT. Cáceres. XVII Simpósio Brasileiro de Geografia Física Aplicada e I Congresso Nacional de Geografia Física. 2017.

PENA, R. F. A. "Assoreamento de rios"; Brasil Escola. 2018. Disponível em $<$ https://brasilescola.uol.com.br/geografia/assoreamento-rios.htm>. Acesso em: 28 de maio de 2019.

SOUZA, P. J. O. P. Avanço da fronteira agrícola na Amazônia: Impactos ambientais sob o ponto de vista climático. Belém: Universidade Federal Rural da Amazônia, 2010.

SILVA NETO, E. C. ; SOUZA, A. F. F.; JÚNIOR, M. G. C.; CORDEIRO, A. A. S.; OLIVEIRA, A. L. Aplicação do sistema de avaliação da aptidão agrícola das Terras (saaat) em solos do norte de Minas Gerais. Agrarian Academy, Centro Científico Conhecer - Goiânia, v.5, n.9; p. 31, 2018.

TAVORA, R. P. A expansão da soja na Amazônia e as suas Consequências. 2015. 48p. Dissertação (Mestrado em Gestão Ambiental) - Universidade Candido Mendes. Niterói-RJ, 2015. 